\title{
Properties and performance of flax yarn/thermoplastic polyester composites
}

\section{Madsen, Bo; Mehmood, Shahid}

Published in:

Journal of Reinforced Plastics \& Composites

Link to article, DOI:

10.1177/0731684412441686

Publication date:

2012

Document Version

Publisher's PDF, also known as Version of record

Link back to DTU Orbit

Citation (APA):

Madsen, B., \& Mehmood, S. (2012). Properties and performance of flax yarn/thermoplastic polyester composites. Journal of Reinforced Plastics \& Composites, 31(24), 1746-1757.

https://doi.org/10.1177/0731684412441686

\section{General rights}

Copyright and moral rights for the publications made accessible in the public portal are retained by the authors and/or other copyright owners and it is a condition of accessing publications that users recognise and abide by the legal requirements associated with these rights.

- Users may download and print one copy of any publication from the public portal for the purpose of private study or research.

- You may not further distribute the material or use it for any profit-making activity or commercial gain

- You may freely distribute the URL identifying the publication in the public portal

If you believe that this document breaches copyright please contact us providing details, and we will remove access to the work immediately and investigate your claim 


\title{
Properties and performance of flax yarn/ thermoplastic polyester composites
}

Journal of Reinforced Plastics

\author{
Shahid Mehmood' and Bo Madsen ${ }^{2}$
}

(S)AGE

\begin{abstract}
Aiming at demonstrating the potential of unidirectional natural fiber-reinforced thermoplastic composites in structural applications, textile flax yarn/thermoplastic polyester composites with variable fiber volume fractions have been manufactured by a filament-winding process followed by a vacuum-assisted compression molding process. The microstructure of the composites shows that the flax fiber yarns are well impregnated by the polyester matrix, and this supports the measured low porosity content of the composites. The experimental tensile modulus and ultimate tensile stress of the composites in the axial and transverse directions are well simulated by rule of mixtures models. In the axial direction, at a fiber volume fraction of 0.50 , the experimental tensile modulus and ultimate tensile stress are $32 \mathrm{GPa}$ and $350 \mathrm{MPa}$, respectively. In comparison, for glass fiber composites at a fiber volume fraction of 0.50 , the tensile modulus and ultimate tensile stress are calculated to be $38 \mathrm{GPa}$ and $1800 \mathrm{MPa}$, respectively. The flax yarn composites show better specific tensile modulus than the glass fiber composites with values of $23 \mathrm{GPa} / \mathrm{g} / \mathrm{cm}^{3}$ and $20 \mathrm{GPa} / \mathrm{g} / \mathrm{cm}^{3}$, respectively. An analysis of data from previous studies of unidirectional natural fibre composites demonstrates comparatively good reinforcement efficiency of the flax yarn fibers with an effective tensile modulus and ultimate tensile stress of the fibers in the area of $70 \mathrm{GPa}$ and $800 \mathrm{MPa}$, respectively. Altogether, it is demonstrated that composites with high-quality textile flax yarn are well suited for structural applications when stiffness and weight saving are the central selection criteria.
\end{abstract}

\section{Keywords}

Flax yarn, flax fibers, natural fibers, polyester, thermoplastic, composites, tensile properties

\section{Introduction}

Natural fiber-reinforced thermoplastic composites form a new class of materials that have future potential for use in structural applications as an alternative to traditional materials, such as wood and synthetic fiber composites. The main drivers for development of this new class of materials are environmental concerns, in addition to attractive technical properties, for example, high specific mechanical properties, which are due to a combination of good mechanical properties and low density of natural fibers. Automotive body parts are currently the prime applications, and the automotive engineering industry has therefore provided the direction for further work and improvement of the properties and performance of natural fiber-reinforced thermoplastic composites.

Flax is a type of natural fiber that is widely grown in Europe. The flax fibers show good mechanical properties $^{1}$ and they can be spun to form continuous natural fiber yarns. Using high-quality textile flax yarn together with a matrix of low-melting-temperature thermoplastic polyester, the present study aims to demonstrate the potential of unidirectional natural fiberreinforced thermoplastic composites in structural applications.

\footnotetext{
'School of Engineering, Swansea University, Swansea, UK

${ }^{2}$ Materials Research Division, Risoe National Laboratory for Sustainable Energy, Technical University of Denmark, Roskilde, Denmark

\section{Corresponding author:}

Shahid Mehmood, School of Engineering, Swansea University, Swansea, SA2 8PP, UK.

Email: s.mehmood@swansea.ac.uk
} 


\section{Materials and methods}

The fiber reinforcement used in this study is flax yarn (Smeraldo, Nm 1/9.7, Linificio e Canapificio Nazionale SpA, Italy) commonly used for conventional textile applications. The flax yarn was kindly supplied by Extreme Materials S.R.L., Italy. The dry linear density of the flax yarn was measured to be $88.9 \pm 2.7 \mathrm{~g} / 1000 \mathrm{~m}$. The used matrix thermoplastic polymer is low-melting-temperature polyethylene terephthalate (LPET) in the form of filaments with a measured linear density of $55.5 \pm 1.7 \mathrm{~g} / 1000 \mathrm{~m}$. The LPET filaments were kindly supplied by Comfil ApS, Denmark.

\section{Fiber characteristics}

The density of the flax yarn fibers and the LPET filaments was determined by pycnometry ${ }^{2}$ using water as displacement medium. Polarized optical microscopy was used to assess the amount of defects in the flax fibers.

\section{Yarn characteristics}

The flax yarn was observed by optical microscopy, and Image Pro software was used to measure the fiber twisting angle and the yarn diameter. Five flax yarn samples, each of $10 \mathrm{~mm}$ in length, were observed, and within each sample, the fiber twisting angle and the yarn diameter were measured at 15 locations along the yarn. Altogether, 75 measurements were taken for the two yarn parameters.

\section{Manufacturing of composites}

Unidirectional composites of flax yarn and LPET filaments were manufactured with variable fiber volume fractions. The unidirectional fiber-matrix assemblies were obtained by winding the flax yarn and the LPET filaments on to a rectangular steel frame using a filament-winding process. In order to produce neat matrix assemblies, only the LPET filaments were wound on to the steel frame. Prior to the filament-winding process, the steel frame was treated with a thin layer of Zyvax release agent (Granudam ApS, Denmark). The wound fiber-matrix assemblies were dried in a vacuum oven $\left(0.9 \mathrm{mbar} ; 20^{\circ} \mathrm{C}\right)$ for at least $18 \mathrm{~h}$ to remove moisture. The assemblies were then made into composite plates by vacuum heating (at 3-4 mbar; $200^{\circ} \mathrm{C} ; 15 \mathrm{~min}$ ), followed by press consolidation (at $200 \mathrm{kN} ; 30^{\circ} \mathrm{C} ; 1 \mathrm{~min}$ ). ${ }^{3}$ The planar dimensions of the manufactured composite plates were $430 \mathrm{~mm} \times 120 \mathrm{~mm}$, with thicknesses in the range $2.1-2.4 \mathrm{~mm}$.

\section{Volumetric composition of composites}

The fiber weight fraction $\left(W_{f}\right)$ was determined by the relationship between the number of flax yarns $\left(n_{f}\right)$ and the number of LPET filaments $\left(n_{m}\right)$ used in the filament-winding process, and their linear densities $\left(t e x_{f}\right.$ and $\left.t e x_{m}\right)$, by equation (1)

$$
W_{f}=\frac{n_{f} t e x_{f}}{n_{f} t e x_{f}+n_{m} t e x_{m}}
$$

The nominal fiber volume fraction $\left(V_{f}^{n}\right)$ which was expected prior to manufacturing of the composites was determined by equation (2)

$$
V_{f}^{n}=\frac{\frac{W_{f}}{\rho_{f}}}{\frac{W_{f}}{\rho_{f}}+\frac{\left(1-W_{f}\right)}{\rho_{m}}}
$$

where $\rho_{f}$ is the fiber density and $\rho_{m}$ is the matrix density. The nominal $V_{f}^{n}$ is determined by assuming porosity content as zero. The density of the composites $\left(\rho_{c}\right)$ was determined by the buoyancy method ${ }^{4}$ using water as the displacement medium. The correct volume fractions of fibers $\left(V_{f}\right)$, matrix $\left(V_{m}\right)$, and porosity $\left(V_{p}\right)$ were determined using equations (3)-(5)

$$
\begin{gathered}
V_{f}=W_{f} \frac{\rho_{c}}{\rho_{f}} \\
V_{m}=\left(1-W_{f}\right) \frac{\rho_{c}}{\rho_{m}} \\
V_{p}=1-\left(V_{f}+V_{m}\right)
\end{gathered}
$$

\section{Microstructure of composites}

The microstructure of the composites was investigated by optical microscopy of polished composite cross sections. Samples with planar dimensions of $15 \mathrm{~mm} \times 26 \mathrm{~mm}$ were cut from the central part of the composite plates. The samples were ground on the side perpendicular to the fiber direction using silicon carbide papers (\#1000 for $9 \mathrm{~min}$ and \#4000 for $25 \mathrm{~min}$; using water as a lubricating agent), followed by final polishing using $1 \mu \mathrm{m}$ diamond paste for $10 \mathrm{~min}$.

\section{Mechanical properties of composites}

Two types of dumbbell-shaped specimens were cut from the composite plates by computerized numerically controlled (CNC) milling (using water as coolant to avoid localized thermal degradation of fibers and matrix melting): (a) $180 \mathrm{~mm} \times 25 \mathrm{~mm}$ with gauge section $30 \mathrm{~mm} \times 15 \mathrm{~mm}$ for specimens with the yarn axis 


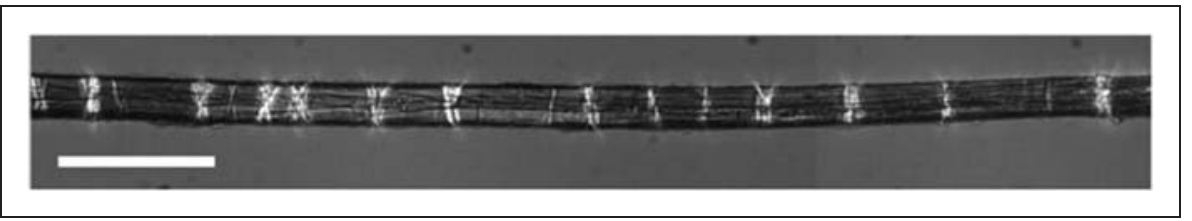

Figure I. Optical microscope image of a flax fiber with defects (scale bar is $100 \mu \mathrm{m}$ ).

along the loading direction, that is, $0^{\circ}$, and (b) $115 \mathrm{~mm} \times 25 \mathrm{~mm}$ with gauge section $30 \mathrm{~mm} \times 15 \mathrm{~mm}$ for specimens with their yarn axis transverse to the loading direction, that is, $90^{\circ}$.

Prior to tensile testing, all the specimens were conditioned at $50 \%$ relative humidity and $23^{\circ} \mathrm{C}$ until moisture equilibrium was achieved (i.e. until the weights of the specimens were stabilized), and this took approximately 70 days. All handling and testing of the conditioned specimens outside the controlled climate was carried out within a maximum of $40 \mathrm{~min}$. Tensile tests were performed on an Instron testing machine with the following test specifications: load cell $20 \mathrm{kN}$ and crosshead speed $2 \mathrm{~mm} / \mathrm{min}$. From each composite plate, a total of eight specimens were tested: four specimens in the axial direction and four specimens in the transverse direction. Prior to testing, the width and thickness of the specimens at the gauge section were measured at three different positions with a micrometer screw $( \pm .01 \mathrm{~mm})$, allowing the crosssectional area to be determined. No tabs were used, but instead a steel mesh was used to increase the friction in the grips. Strain was measured by positioning two extensometers on each side of the specimens at the gauge section. Tensile modulus (GPa, linear regression between strain 0.01 and $0.10 \%$ ), ultimate tensile stress (UTS; MPa, maximum tensile stress), and strain at UTS (\%) were determined from the measured stress-strain curves. The specific (weight-based) tensile modulus and UTS were determined by dividing by the measured density of the composites.

\section{Results and discussions}

\section{Fiber characteristics}

The density of the flax yarn fibers and the LPET filaments were measured to be $1.589 \pm 0.045 \mathrm{~g} / \mathrm{cm}^{3}$ and $1.357 \pm 0.013 \mathrm{~g} / \mathrm{cm}^{3}$, respectively. Since water was used as displacement medium in the pycnometry measurements, the obtained density of the flax fibers is assumed to represent the density of the cell wall. The cell wall density of natural fibers is governed by their cellulose content; the higher the cellulose content, the higher the cell wall density. The maximum cell wall density equals the density of crystalline cellulose ${ }^{5}$ which is estimated to be $1.64 \mathrm{~g} / \mathrm{cm}^{3}$. Thus, based on these considerations,

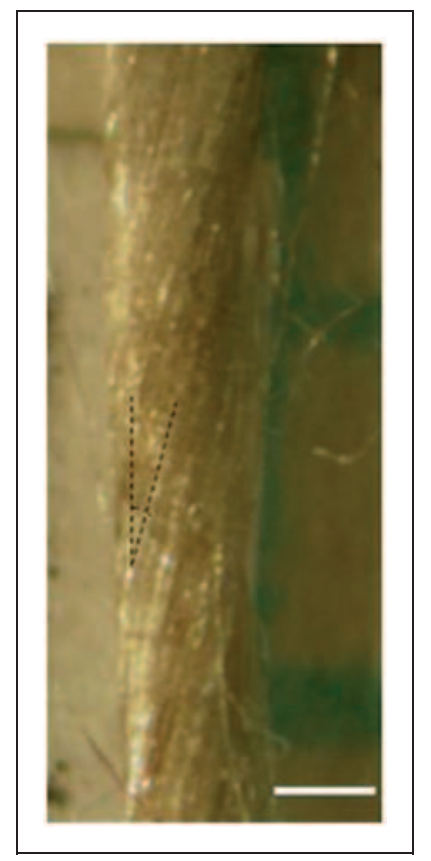

Figure 2. Optical microscope image of the flax yarn (scale bar is $250 \mu \mathrm{m})$.

the relative high density of $1.59 \mathrm{~g} / \mathrm{cm}^{3}$ measured for the flax fibers suggests that they have a high cellulose content. This is supported by a study of textile hemp yarn fibers, where the fiber density was measured to be in the range $1.58-1.60 \mathrm{~g} / \mathrm{cm}^{3}$, and with a measured high cellulose content of the fibers in the range $88-91 \mathrm{w} / \mathrm{w} \%{ }^{6}$

Figure 1 shows a representative image of a flax fiber from the textile yarn. The fiber defects can be seen as bright lines across the fiber. It is believed that such defects are local misalignments of cellulose microfibrils in the cell wall. Such defects are denoted by different names, for example, nodes, kink bands, slip planes, misaligned zones or microcompressions. ${ }^{7}$ In a recent study, ${ }^{8}$ it has been shown that the defect content in flax fibers is increased due to processing of the fibers. In another study of flax and hemp fibers, ${ }^{9}$ the increasing numbers of processing steps were correlated with a decrease in strength of the fibers. Thus, it must be considered that the performance of natural fiber-reinforced thermoplastic composites is highly dependent on the amount of defects in the fibers generated during their processing because these defects act as stress raisers ${ }^{10}$ 
in the polymer matrix of the composite causing fiber failure $^{11}$ and debonding at the fiber-matrix interface. ${ }^{10}$ Further work is needed to modify the currently applied fiber-processing techniques for textile yarns (e.g. retting, scutching, carding, and spinning), in order to obtain natural fibers with lower defect content.

\section{Yarn characteristics}

Figure 2 shows that the flax fibers in the yarn are twisted with a right-handed angle to the axis of the yarn. Madsen et al. ${ }^{6}$ have also observed this kind of twist in a study of hemp yarn. If the fibers are twisted at a right-handed angle to the yarn axis, then the yarn is said to have Z-twist and if twisted at a left-handed angle, then it is said to have S-twist.

The results of the measurements for fiber twisting angle and yarn diameter are shown in Figure 3. It is demonstrated that both the fiber twisting angle and the yarn diameter are not constant, but they exhibit variation along the yarn. The reason for the observed large

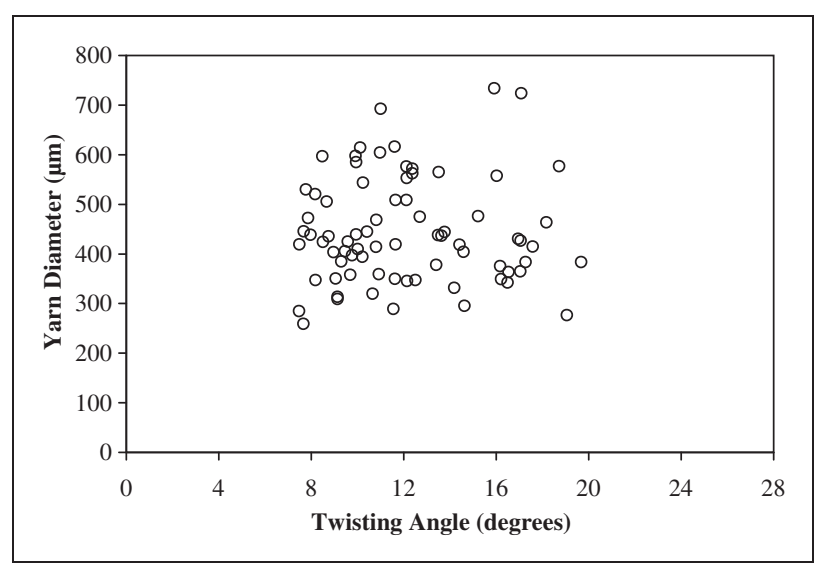

Figure 3. Flax yarn diameter as a function of fiber twisting angle. variation in the two yarn parameters is that flax fibers, in contrast to synthetic fibers, are not uniform entities and a certain degree of variation must therefore be accepted in the yarns. The results shown in Figure 3 do not, however, indicate that the two yarn parameters are correlated with each other. The mean $\pm \mathrm{SD}$ for the twisting angle is $12.1 \pm 3.3^{\circ}$, and the mean \pm SD for the yarn diameter is $445 \pm 107 \mu \mathrm{m}$. Similar results for twisting angle and yarn diameter have been reported by Madsen et al. ${ }^{6}$ for two types of hemp yarns.

By assuming that the cross-sectional area of the flax yarn is circular (see Figure 4(a)), the apparent crosssectional area of the yarn (the total area of fibers and space between fibers) can be calculated from the mean yarn diameter to be $155,584 \mu \mathrm{m}^{2}$. The absolute crosssectional area of the yarn (which includes only the area of fibers) can be calculated from the linear density of the yarn and the fiber density to be $55,632 \mu \mathrm{m}^{2}$. The ratio between the absolute and the apparent crosssectional areas is known as the degree of yarn compaction, and it can then be determined to be 0.38 for the flax yarn. In a previous study of hemp yarn, ${ }^{6}$ the degree of yarn compaction was determined to be 0.65 . Therefore, it is demonstrated that the flax yarn in the present study is less compact than the given hemp yarn, which accordingly should make it easier to impregnate the flax yarn by the matrix polymer. Thus, the degree of yarn compaction can be used as a quantitative parameter to assess the permeability of a yarn with respect to being impregnated by a matrix polymer.

\section{Volumetric composition of composites}

Table 1 shows the results of the measured volumetric compositions of the composites. The manufactured six composite plates show fiber volume fractions in the range $0.206-0.539$, and porosity in the range $0.032-0.066$. There is a slight overestimation of the

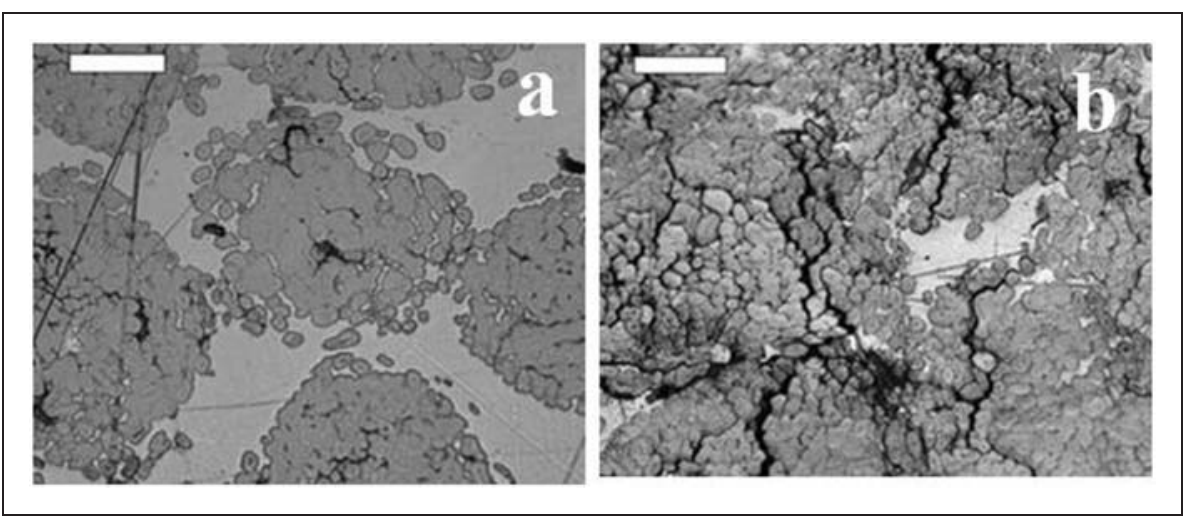

Figure 4. Optical microscope images showing cross sections of flax/low-melting-temperature polyethylene terephthalate (LPET) composites with fiber volume fractions of (a) 0.38 and (b) 0.54 . Scale bar is $100 \mu \mathrm{m}$. 
nominal fiber volume fractions $\left(V_{f}^{n}\right)$ with respect to the correct values $\left(V_{f}\right)$, and this is attributed to the occurrence of porosity in the composites. Porosity is typically observed in natural fiber composites. ${ }^{5}$ The porosity in the composites can be seen to increase when the fiber volume fraction is increased, and this has previously been analyzed by a volumetric interaction model developed for composite materials. ${ }^{12}$

In Table 1, it can be seen that the composite plates CP01 and CP03 have an identical fiber weight fraction of 0.348 , since they were manufactured with an equivalent number of flax yarns and LPET filaments (equation (1)). The resulting volumetric composition of these two plates, CP01 and CP03, is almost identical, with fiber volume fractions of 0.300 and 0.303 , and with porosities of 0.041 and 0.032 , respectively. Thus, it is demonstrated that the quality of the flax yarn is sufficiently uniform to permit manufacture of identical composite plates.

The content of porosity in the LPET plates is calculated to be 0.015 by using the equations (3)-(5) based on the difference between the measured density of LPET in filament form and in molded plate form $\left(1.357\right.$ vs. $\left.1.337 \mathrm{~g} / \mathrm{cm}^{3}\right)$. Thus, LPET is a well-suitable polymer matrix in composites manufactured by the compression-molding technique resulting in a matrix phase with a very small porosity content, which likely is situated in the form of entrapped small air bubbles.

\section{Microstructure of composites}

Optical microscope observations of composite cross sections were used to assess the microstructure of the composites. As can be seen in Figure 4(a), showing a representative image of a composite with a medium fiber volume fraction of 0.382 (plate CP09), the flax yarns are well dispersed within the LPET matrix. Moreover, the image shows that the fiber yarns have approximately circular cross sections, and that the fibers are well impregnated with the matrix with only a few occurrences of porosities (i.e. black areas) inside the yarns. The low impregnation porosity is well correlated with the determined low degree of yarn compaction of 0.38 .

Figure 4(b) shows an image of a composite with a high fiber volume fraction of 0.539 , and a high porosity of 0.066 (plate CP11). It can be seen that the fiber yarns are closely packed, and that the LPET matrix has not

Table I. Volume fractions of fibers, matrix, and porosity in the flax/LPET composites. Shown are also the measured densities and fiber weight fractions that are used to determine the volumetric compositions

\begin{tabular}{|c|c|c|c|c|c|c|}
\hline \multirow[b]{2}{*}{ Plate no } & \multirow{2}{*}{$\begin{array}{l}\text { Density } \\
\rho_{c}\left(\mathrm{~g} / \mathrm{cm}^{3}\right)\end{array}$} & \multirow{2}{*}{$\begin{array}{l}\text { Fiber weight fraction } \\
W_{f}\end{array}$} & \multicolumn{4}{|c|}{ Volume fractions } \\
\hline & & & $V_{f}^{n}$ & $V_{f}$ & $V_{m}$ & $V_{p}$ \\
\hline CPI2 & $\mathrm{I} .337$ & 0.000 & 0.000 & 0.000 & 0.985 & 0.015 \\
\hline СР08 & $\mathrm{I} .349$ & 0.243 & 0.215 & 0.206 & 0.753 & 0.041 \\
\hline CPOI & $1.37 \mid$ & 0.348 & 0.313 & 0.300 & 0.659 & 0.041 \\
\hline $\mathrm{CPO3}$ & 1.384 & 0.348 & 0.313 & 0.303 & 0.665 & 0.032 \\
\hline СР09 & 1.366 & 0.445 & 0.406 & 0.382 & 0.559 & 0.059 \\
\hline CPIO & 1.404 & 0.546 & 0.506 & 0.482 & 0.470 & 0.048 \\
\hline CPII & 1.392 & 0.616 & 0.578 & 0.539 & 0.394 & 0.066 \\
\hline
\end{tabular}

LPET: low-melting-temperature polyethylene terephthalate.

Table 2. Mechanical properties of the flax/LPET composites tested in the axial direction $\left(0^{\circ}\right)$

\begin{tabular}{llllll}
\hline Plate no & Testing direction & $V_{f}$ & Tensile modulus $(\mathrm{GPa})$ & UTS (MPa) & Strain at UTS (\%) \\
\hline CPI2 & $0^{\circ}$ & 0.000 & $2.7 \pm 0.4$ & $37.8 \pm 1.5$ & $1.36 \pm 0.06$ \\
CP08 & $0^{\circ}$ & 0.206 & $17.1 \pm 0.4$ & $209 \pm 6$ & $1.88 \pm 0.06$ \\
CP0I & $0^{\circ}$ & 0.300 & $22.8 \pm 0.4$ & $258 \pm 7$ & $1.97 \pm 0.08$ \\
CP03 & $0^{\circ}$ & 0.303 & $22.4 \pm 0.2$ & $263 \pm 4$ & $1.97 \pm 0.05$ \\
CP09 & $0^{\circ}$ & 0.382 & $27.6 \pm 2.2$ & $292 \pm 7$ & $1.76 \pm 0.12$ \\
CPI0 & $0^{\circ}$ & 0.482 & $32.0 \pm 2.9$ & $344 \pm 21$ & $1.75 \pm 0.13$ \\
CPII & $0^{\circ}$ & 0.539 & $32.6 \pm 5.4$ & $293 \pm 70$ & $1.54 \pm 0.37$ \\
\hline
\end{tabular}

LPET: low-melting-temperature polyethylene terephthalate; UTS: ultimate tensile stress. 
Table 3. Mechanical properties of the flax/LPET composites tested in the transverse direction $\left(90^{\circ}\right)$

\begin{tabular}{llllll}
\hline Panel no & Testing direction & $V_{f}$ & Tensile modulus $(\mathrm{GPa})$ & UTS (MPa) & Strain at UTS (\%) \\
\hline CPI2 & $90^{\circ}$ & 0.000 & $2.8 \pm 0.1$ & $45.7 \pm 1.3$ & $1.86 \pm 0.20$ \\
CP08 & $90^{\circ}$ & 0.206 & $3.2 \pm 0.0$ & $16.8 \pm 0.9$ & $0.85 \pm 0.14$ \\
CPOI & $90^{\circ}$ & 0.300 & $2.9 \pm 0.2$ & $13.2 \pm 0.5$ & $0.81 \pm 0.18$ \\
CP03 & $90^{\circ}$ & 0.303 & $3.2 \pm 0.0$ & $15.4 \pm 0.6$ & $0.68 \pm 0.02$ \\
CP09 & $90^{\circ}$ & 0.382 & $3.2 \pm 0.0$ & $12.0 \pm 0.8$ & $0.46 \pm 0.04$ \\
CPI0 & $90^{\circ}$ & 0.482 & $3.6 \pm 0.1$ & $13.2 \pm 1.6$ & $0.42 \pm 0.05$ \\
CPII & $90^{\circ}$ & 0.539 & $3.1 \pm 0.1$ & $9.6 \pm 0.5$ & $0.52 \pm 0.08$ \\
\hline
\end{tabular}

LPET: low-melting-temperature polyethylene terephthalate; UTS: ultimate tensile stress.

been able to sufficiently impregnate all the fibers in the yarns. This situation is related to that the fiber volume fraction is close to the maximum obtainable fiber volume fraction, and this results in an increase of the porosity content. A more detailed and quantitative analysis of this behavior in the flax/LPET composites is addressed by the authors in an ongoing study.

\section{Mechanical properties of composites}

The measured mechanical properties of the six composite plates are shown in Tables 2 and 3. In the axial direction (Table 2), the tensile modulus is in the range $17-33 \mathrm{GPa}$, UTS is in the range $209-344 \mathrm{MPa}$, and strain at UTS is in the range $1.5-2.0 \%$. In the transverse direction (Table 3), the tensile modulus is in the range 2.9-3.6 GPa, UTS is in the range 10-17 MPa, and strain at UTS is in the range $0.4-0.9 \%$. In addition to the expected large difference in properties between the two directions, due to the anisotropic nature of unidirectional composites, it can also be seen that the influence of fiber content is more marked when the composites are tested in the axial direction. This will be analyzed in the following sections by micromechanical models.

Tables 2 and 3 also show that the manufactured two composite plates, $\mathrm{CP} 01$ and $\mathrm{CP} 03$, with identical fiber weight fractions and volumetric compositions (Table 1), have almost identical mechanical properties. In the axial direction, tensile modulus and UTS are measured to be 22.8 vs. $22.4 \mathrm{GPa}$ and 258 vs. $263 \mathrm{MPa}$, respectively, for the two plates. Thus, it is demonstrated that by using the same batch of textile flax yarn, together with a well-controlled compositemanufacturing technique, composite plates with identical technical performance can be produced.

\section{Axial tensile properties}

The axial tensile modulus, UTS, and strain at UTS of the composites (Table 2) are plotted as a function the fibre volume fraction in Figures 5, 6, and 7,

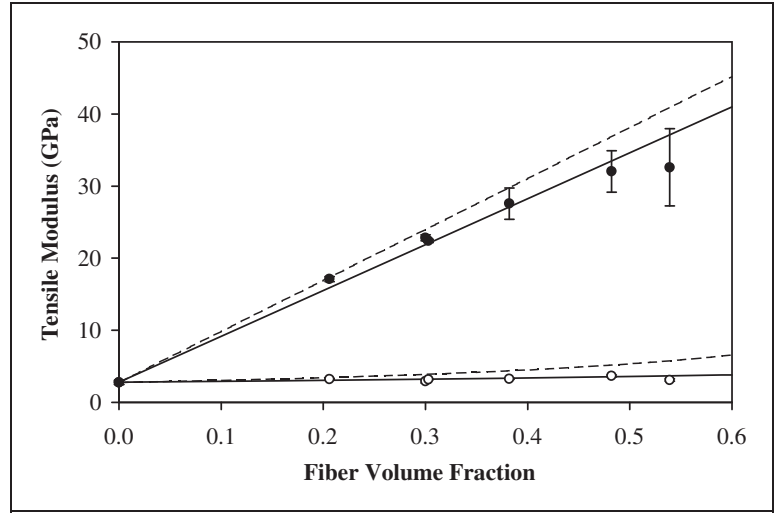

Figure 5. Tensile modulus of unidirectional flax/low-meltingtemperature polyethylene terephthalate (LPET) composites vs. fiber volume fraction. Data points are experimental tensile modulus in the axial direction (O) and in the transverse direction $(\bigcirc)$. Lines are rule of mixtures model simulations for the flax/ LPET composites (solid lines) and glass/LPET composites (dotted lines).

respectively. In the case of unidirectional composites, the axial tensile modulus $(E)$ and $\operatorname{UTS}(\sigma)$ are traditionally calculated by the rule of mixtures model:

$$
E_{c 1}=E_{f 1} V_{f}+E_{m}\left(1-V_{f}\right)
$$

where $E$ can be replaced by $\sigma$. The tensile modulus of the LPET matrix $\left(E_{m}\right)$ is measured to be $2.8 \mathrm{GPa}$ (Tables 2 and 3, grand mean value, assuming isotropic properties). By using equation (6), the effective axial tensile modulus of the fibers $\left(E_{f 1}\right)$ can be calculated for the six composites to give a mean value of $66 \mathrm{GPa}$. In Figure 5, the solid model line of the axial tensile modulus is made by inserting the determined values of $E_{m}$ and $E_{f 1}$ in equation (6). By using a similar approach for the UTS; $\sigma_{m}$ and $\sigma_{f 1}$ are determined to be $42 \mathrm{MPa}$ and $710 \mathrm{MPa}$, respectively. In Figure 6, the solid model line of the axial UTS is made by inserting the determined values of $\sigma_{m}$ and $\sigma_{f 1}$ in equation (6). 
In both Figures 5 and 6 , it can be observed that the experimental axial tensile modulus and UTS for the composites are generally in good agreement with the model lines. However, for the composites with high fiber volume fractions $\left(V_{f}>0.40\right)$, the experimental data tend to slightly deviate from the linear relationship predicted by the rule of mixtures model. This is due to the increasing porosity content in the composites when the fiber content is increased, ${ }^{12}$ and this effect for

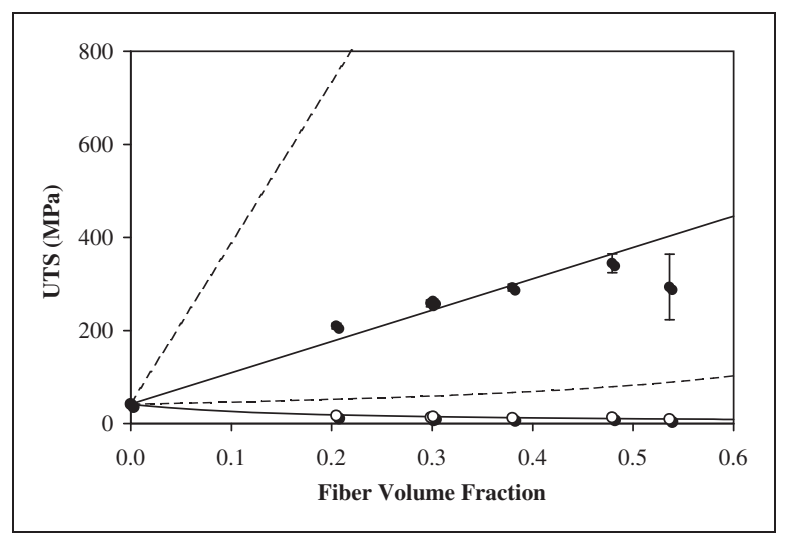

Figure 6. Ultimate tensile stress (UTS) of unidirectional flax/low-melting-temperature polyethylene terephthalate (LPET) composites vs. fiber volume fraction. Data points are experimental UTS in the axial direction (O) and in the transverse direction $(\bigcirc)$. Lines are rule of mixtures model simulations for the flax/LPET composites (solid lines) and glass/LPET composites (dotted lines). the flax/LPET composites is addressed in an ongoing study by the authors. In the present study, however, the analysis of the mechanical properties is carried out by assuming that the composites have a porosity content of zero.

For means of comparison, the axial tensile modulus and UTS of unidirectional glass fiber/LPET composites are calculated by inserting typical values of $73 \mathrm{GPa}$ and $3500 \mathrm{MPa}$ for $E_{f 1}$ and $\sigma_{f 1}$, respectively, for glass fibers in equation (6). The dotted lines in Figures 5 and 6 are model lines for the glass fiber/LPET composites. It can be observed that the tensile modulus of the two composites are comparable (due to the almost similar $E_{f 1}$ values of 73 vs. $66 \mathrm{GPa}$ ), but the UTS for the glass fiber composites is by far larger than the flax fiber composites (due to the large difference in $\sigma_{f 1}$ values of 3500 vs. $710 \mathrm{MPa}$ ). At a fiber volume fraction of 0.50 , tensile modulus and UTS for the two composites are 32 vs. $38 \mathrm{GPa}$ and 350 vs. $1800 \mathrm{MPa}$, respectively.

In Figure 7, the axial strain at UTS of the flax fiber/ LPET composites is plotted as a function of the fiber volume fraction. No clear effect of a changed fiber volume fraction can be observed. The mean axial strain at UTS for all the composites is $1.81 \%$, and this can be assumed to correspond to the strain at UTS for the flax fibers. A similar observation has been made for unidirectional hemp yarn fiber composites where the strain at UTS also was found to be almost constant with a mean of $1.79 \%$ for composites with variable fiber volume fractions. ${ }^{13}$

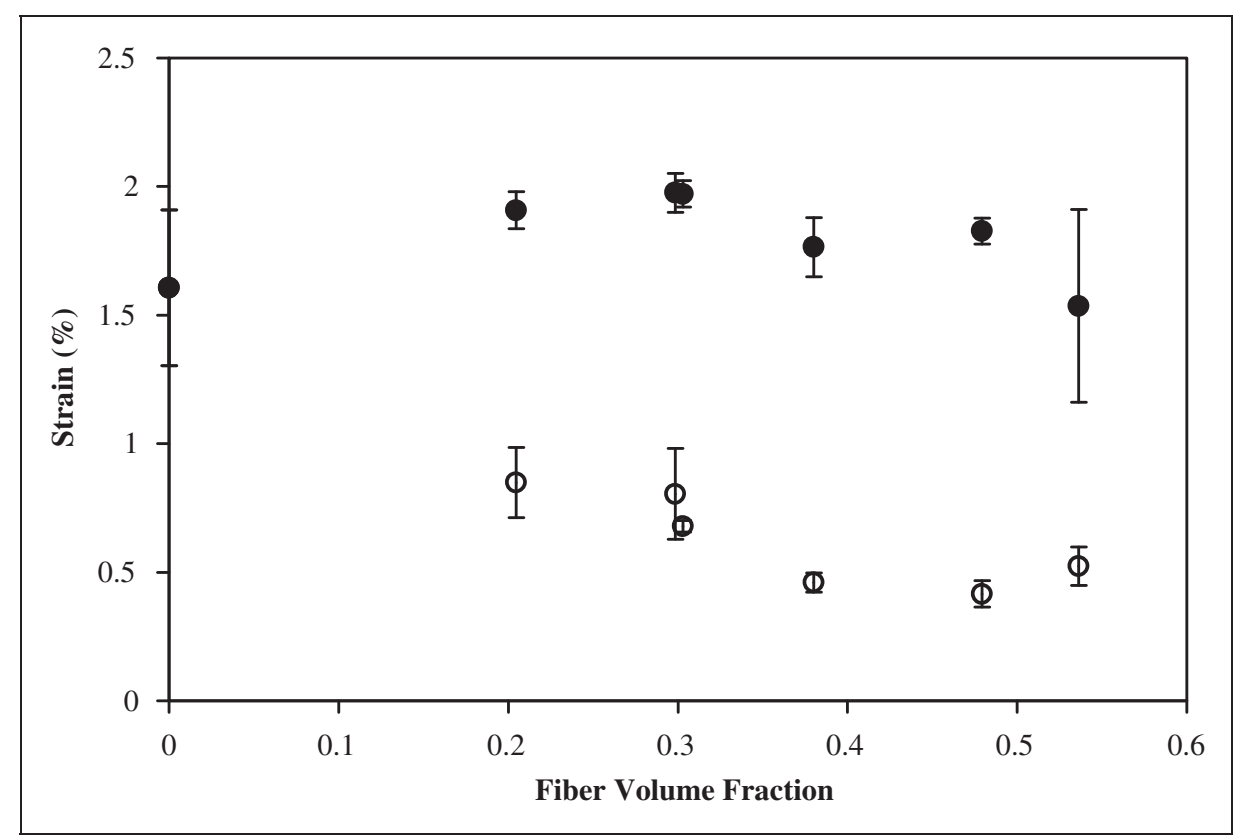

Figure 7. Strain at ultimate tensile stress (UTS) of unidirectional flax/low-melting-temperature polyethylene terephthalate (LPET) composites vs. fiber volume fraction. Data points are experimental strain at UTS in the axial direction (O) and in the transverse direction $(\bigcirc)$. 


\section{Transverse tensile properties}

In Figures 5-7, the transverse tensile properties of the unidirectional flax/LPET composites are presented together with the axial ones. Transverse tensile modulus and UTS of unidirectional composites are traditionally calculated by the 'inverse' rule of mixtures model

$$
\frac{1}{E_{c 2}}=\frac{1}{E_{f 2}} V_{f}+\frac{1}{E_{m}}\left(1-V_{f}\right)
$$

where $E$ can be replaced by $\sigma$. The tensile modulus of the LPET matrix $\left(E_{m}\right)$ is measured to be $2.8 \mathrm{GPa}$ (Tables 2 and 3, grand mean value, assuming isotropic properties). By using equation (7), the effective transverse tensile modulus of the fibers $\left(E_{f 2}\right)$ can be calculated for the six composites to give a mean value of $5 \mathrm{GPa}$. In Figure 5, the solid model line of the transverse tensile modulus is made by inserting the determined values of $E_{m}$ and $E_{f 2}$ in equation (7). By using a similar approach for the transverse UTS; $\sigma_{m}$ and $\sigma_{f 2}$ are determined to be $42 \mathrm{MPa}$ and $6 \mathrm{MPa}$, respectively. In Figure 6, the solid model line of the transverse UTS is made by inserting the determined values of $\sigma_{m}$ and $\sigma_{f 2}$ in equation (7).

Based on the estimated values of the axial and transverse tensile modulus of the flax fibers $\left(E_{f 1}=66 \mathrm{GPa}\right.$, $E_{f 2}=5 \mathrm{GPa}$ ), the ratio of anisotropy of the flax fibers can be calculated to be $13(=66 / 5)$. In previous studies, using more advanced micromechanical models, ${ }^{13-15}$ the ratio of anisotropy for natural fibers has been estimated in the range 7-9.

The dotted lower lines in Figures 5 and 6 are model lines for the transverse properties of glass fiber/ LPET composites. Due to the isotropic nature of glass fibers, values of $E_{f 2}$ and $\sigma_{f 2}$ were set to be $73 \mathrm{GPa}$ and $3500 \mathrm{MPa}$, which are identical to the ones used in the axial direction. The model lines are clearly demonstrating that the transverse tensile modulus and UTS of flax and glass fiber composites are not much different from each other. This is explained by that the transverse properties of unidirectional fiber composites are mostly influenced by matrix properties when $V_{f}$ is within practical values for composites (see equation (7)).

In Figure 7, the transverse strain at UTS of the flax fiber/LPET composites is decreased as a function of the fiber volume fraction. For low fiber volume fractions, below 0.30 , strain at UTS is about $0.8 \%$; whereas, it is decreased to about $0.5 \%$ when the fiber volume fraction is increased. The lower transverse values of strain at UTS compared with the axial ones can be explained by that the composites are loaded transversely to the fibers, and that they are likely to fail in the less-compliant fiber/matrix interface regions.

\section{Specific tensile properties}

In order to analyze the weight-based performance of the composites, the so-called specific properties are used where the tensile properties are divided by the density of the composites. Accordingly, the specific tensile modulus and UTS of the composites in the axial direction can be calculated by the model

$$
E_{c s p e c}=\frac{E_{c 1}}{\rho_{c}}=\frac{E_{f 1} V_{f}+E_{m}\left(1-V_{f}\right)}{\rho_{f} V_{f}+\rho_{m}\left(1-V_{f}\right)}
$$

where $E$ can be replaced by $\sigma$. Figures 8 and 9 show experimental data together with model lines for the

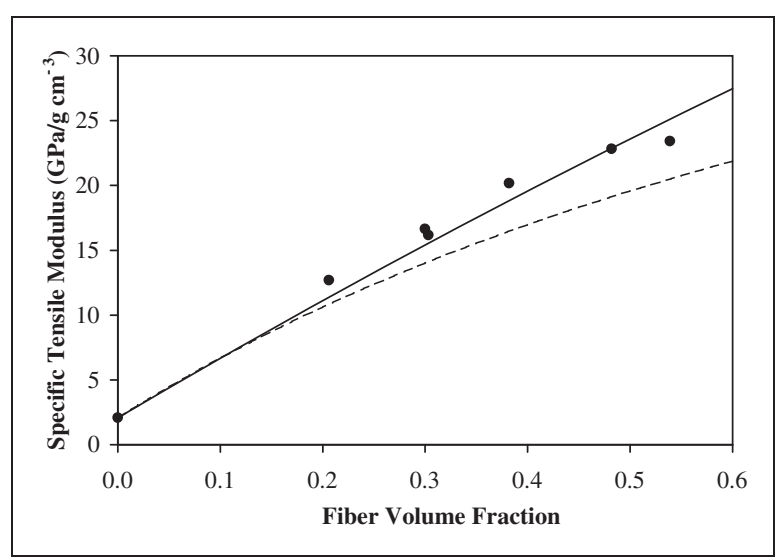

Figure 8. Specific tensile modulus of composites vs. fiber volume fraction. Data points are experimental data for flax/ low-melting-temperature polyethylene terephthalate (LPET) composites. Lines are rule of mixtures model simulations for the flax/LPET composites (solid lines) and glass/LPET composites (dotted lines).

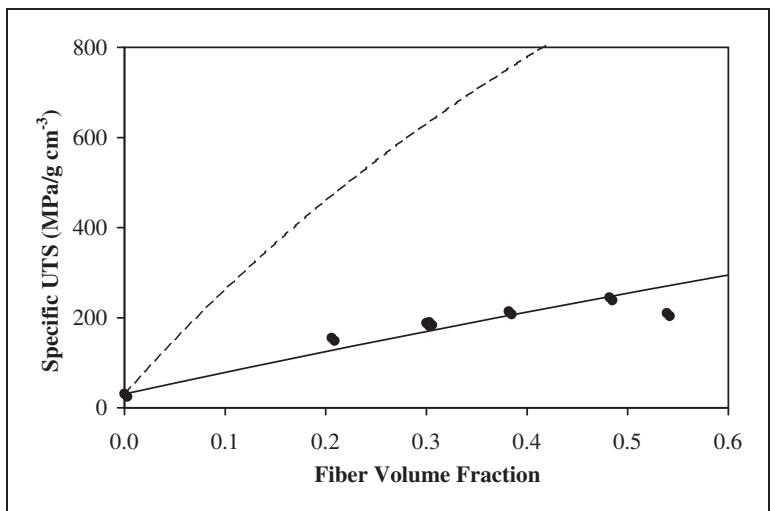

Figure 9. Specific ultimate tensile stress (UTS) of composites vs. fiber volume fraction. Data points are experimental data for flax/low-melting-temperature polyethylene terephthalate (LPET) composites. Lines are rule of mixtures model simulations for the flax/LPET composites (solid lines) and glass/LPET composites (dotted lines). 
specific tensile modulus and UTS of the flax/LPET composites. For means of comparison, shown are also model lines for glass/LPET composites (using values of $E_{f 1}, \sigma_{f 1}$, and $\rho_{f}$ of $73 \mathrm{GPa}, 3500 \mathrm{MPa}$, and $2.54 \mathrm{~g} / \mathrm{cm}^{3}$, respectively, for glass fibers). It can be observed that the model lines are well simulating the experimental data for the flax/LPET composites. With a high fiber volume fraction of 0.50 , the specific tensile modulus and UTS are $23 \mathrm{GPa} / \mathrm{g} / \mathrm{cm}^{3}$ and $250 \mathrm{MPa} / \mathrm{g} / \mathrm{cm}^{3}$, respectively. For the glass/LPET composites, at the same fiber volume fraction, the calculated values of specific tensile modulus and UTS are $20 \mathrm{GPa} / \mathrm{g} / \mathrm{cm}^{3}$ and $900 \mathrm{MPa} / \mathrm{g} /$ $\mathrm{cm}^{3}$, respectively. Thus, on a weight-basis, the flax fibre composites show better tensile modulus than the glass fiber composites. However, as can be observed in Figure 8, this is only the case for composites with a $V_{f}$ above a certain threshold value of about 0.20 . As expected from the very large difference in UTS between the composites (as shown in Figure 6), the specific UTS of the glass fiber composites is still much larger than for the flax fiber composites, despite the lower density of the flax fibers.

Altogether, the results demonstrate that for a given required stiffness of a materials component, flax fiber composites need a slightly larger volume (Figure 5), but resulting in a lower weight (Figure 8) than glass fiber composites.

\section{Literature data on tensile properties of unidirectional natural fiber composites}

A number of studies in the literature have reported axial tensile properties of unidirectional natural fiber composites. Based on a selection of 16 studies,

Table 4. Literature data on the axial tensile properties of unidirectional natural fiber composites. The data are grouped with respect to the values of the back-calculated effective tensile modulus of the fibers

\begin{tabular}{|c|c|c|c|c|c|c|c|}
\hline \multirow[b]{2}{*}{ Fiber type } & \multirow[b]{2}{*}{ Matrix type } & \multirow[b]{2}{*}{$V_{f}$} & \multicolumn{2}{|c|}{ Tensile modulus (GPa) } & \multicolumn{2}{|l|}{ UTS (MPa) } & \multirow[b]{2}{*}{ Reference } \\
\hline & & & Composites & Fibers $^{b}$ & Composites & Fibers $^{b}$ & \\
\hline Flax & Epoxy & 0.26 & 7 & 18 & 105 & 262 & 16 \\
\hline Sisal & Epoxy & 0.30 & 9 & 23 & 200 & 550 & 17 \\
\hline Jute $^{a}$ & Polyester & 0.40 & 8 & 16 & 150 & 300 & 18 \\
\hline Hemp & Epoxy & 0.20 & 8 & 28 & 90 & 250 & 19 \\
\hline Sunhemp & Polyester & 0.30 & 13 & 36 & 125 & 300 & 20 \\
\hline $\int_{u t e}{ }^{a}$ & Epoxy & 0.30 & 14 & 40 & - & - & 14 \\
\hline$J_{u t e}{ }^{a}$ & Epoxy & 0.33 & 15 & 39 & 100 & 202 & 21 \\
\hline Sisal & Epoxy & 0.35 & 15 & 37 & 180 & 421 & 22 \\
\hline Flax & PLA & 0.22 & 14 & 53 & - & - & 23 \\
\hline Flax & PLA & 0.30 & 17 & 49 & - & - & 23 \\
\hline Jute $^{\mathrm{a}}$ & Epoxy & 0.30 & 17 & 50 & 120 & 283 & 24 \\
\hline$J_{u t e^{a}}$ & Polyester & 0.31 & 20 & 58 & 170 & 437 & 25 \\
\hline $\mathrm{Hemp}^{\mathrm{a}}$ & LPET & 0.40 & 24 & 56 & 254 & 560 & 13 \\
\hline Flax $^{\mathrm{a}}$ & Epoxy & 0.40 & 25 & 58 & 140 & 275 & 26 \\
\hline Flax $^{a}$ & PP & 0.43 & 27 & 59 & 251 & 517 & 27 \\
\hline $\mathrm{Flax}^{\mathrm{a}}$ & LPET & 0.21 & 17 & 71 & 210 & 828 & Present study \\
\hline Hemp ${ }^{c}$ & Epoxy & 0.26 & 20 & 68 & 122 & 327 & 28 \\
\hline Flax $^{\mathrm{a}}$ & LPET & 0.30 & 22 & 67 & 263 & 757 & Present study \\
\hline Flax $^{\mathrm{a}}$ & LPET & 0.38 & 28 & 67 & 292 & 687 & Present study \\
\hline $\mathrm{Hemp}^{c}$ & Epoxy & 0.22 & 20 & 80 & 129 & 409 & 28 \\
\hline $\mathrm{Hemp}^{c}$ & Epoxy & 0.29 & 25 & 79 & $|5|$ & 398 & 28 \\
\hline Flax & Epoxy & 0.21 & 22 & 93 & 195 & 740 & 29 \\
\hline $\mathrm{Hemp}^{c}$ & Epoxy & 0.32 & 30 & 87 & 174 & 438 & 28 \\
\hline
\end{tabular}

LPET: low-melting-temperature polyethylene terephthalate; UTS: ultimate tensile stress; PLA: polylactic acid; PP: polypropylene.

${ }^{\text {a } T e x t i l e ~ y a r n . ~}$

${ }^{\mathrm{b} E f f e c t i v e}$ tensile modulus/UTS of the fibers, back-calculated by equation (6) using $E_{m}=3 \mathrm{GPa}$ and $\sigma_{m}=50 \mathrm{MPa}$.

${ }^{\mathrm{c}}$ The hemp fibers in the three groups with $E_{f}$ approximately 70,80 , and $90 \mathrm{GPa}$ are unprocessed, water retted, and fungal retted, respectively. ${ }^{28}$ 


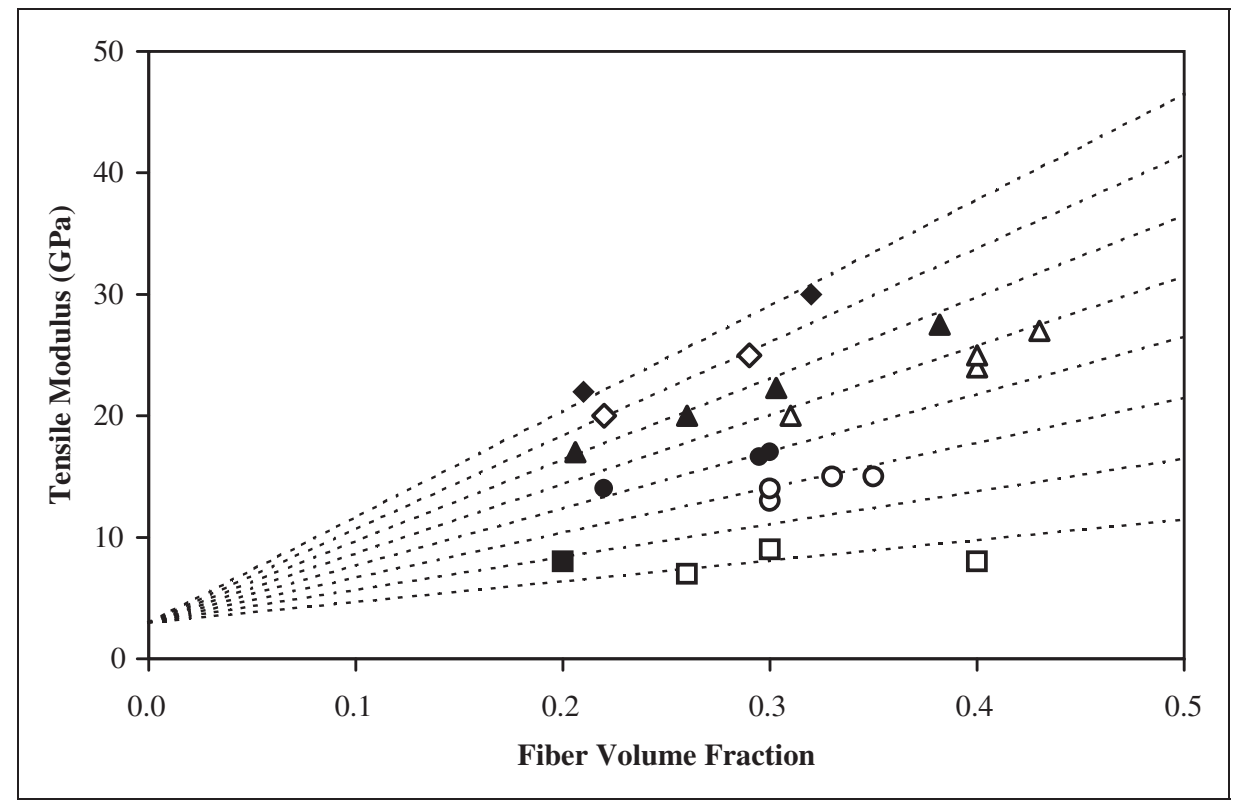

Figure 10. Literature data on the axial tensile modulus of unidirectional natural fiber composites as a function of the fiber volume fraction. The data are grouped according to the back-calculated effective tensile modulus of the fibers $\left(E_{f 1}, G P a\right): 20(\square), 30(\square), 40$ $(\bigcirc), 50(\diamond), 60(\triangle), 70(\Delta), 80(\diamond)$ and $90(\diamond)$, and rule of mixtures model lines are made using the indicated $E_{f 1}$ values, and a constant $E_{m}$ of $3 \mathrm{GPa}$.

Table 4 presents experimental data on tensile modulus and UTS of composites with different types of fibers (flax, hemp, sisal, jute, sunhemp) and matrices (epoxy, polyester, LPET, polylactic acid, polypropylene), and with variable fiber volume fractions $(0.21-0.40)$. By using equation (6), the effective tensile modulus and UTS of the fibers $\left(E_{f 1}\right.$ and $\left.\sigma_{f 1}\right)$ are back-calculated. For means of simplicity, the matrix properties, $E_{m}$ and $\sigma_{m}$, are approximated to be $3.0 \mathrm{GPa}$ and $50 \mathrm{MPa}$, respectively, for all composites. This approximation can be justified by considering that the major part of the load in the axial direction is taken up by the fibers, and small differences in the matrix properties are only causing relative small changes in the back-calculated fiber properties. In Table 4, the data are sorted according to the back-calculated values of $E_{f 1}$ to form eight groups of composites with $E_{f 1}$ values on about 20, 30, 40, 50, 60, 70, 80, and $90 \mathrm{GPa}$.

In Figure 10, the data from the literature studies, including the data from the present study, on tensile modulus of the composites is plotted as a function of the fiber volume fraction. The linear model lines are made by equation (6) using $E_{f 1}$ values of $20,30,40$, 50, 60, 70, 80, and $90 \mathrm{GPa}$, and with a constant $E_{m}$ value of $3.0 \mathrm{GPa}$. As can be observed in the figure, the experimental data originating from the different studies are well located on the model lines. Thus, by this approach, the effect of variable fiber type, matrix type, and fiber volume fraction is normalized, and the span of reinforcement efficiencies of natural fibers is displayed. The best performance is shown by the flax and hemp fibers with an $E_{f 1}$ of about $90 \mathrm{GPa}$ originating from the studies by Oksman ${ }^{29}$ and Thygesen et al. ${ }^{28}$ The second best performance is shown by the hemp fibers with an $E_{f 1}$ of about $80 \mathrm{GPa}$ originating from the study by Thygesen et al. ${ }^{28}$ It can be noted that the fibers from these studies are not in the form of yarns processed by common textile processes, but the fibers have been processed by specially modified processes aimed at obtaining good performing fibers. In the study by Oksman, ${ }^{29}$ the flax fibers were processed by a novel biotechnical process using enzymes and microbial cultures. In the study by Thygesen et al., ${ }^{28}$ the hemp fibers were processed by water and fungal retting under strictly controlled laboratory conditions. The flax yarn fibers in the present study show an $E_{f 1}$ of about $70 \mathrm{GPa}$, and this is still better than the previous studies using natural fiber yarns showing $E_{f 1}$ values with a maximum of only $60 \mathrm{GPa}$.

By a similar approach as used for the tensile modulus, Figure 11 shows the literature data on UTS as a function of the fiber volume fraction. The data are sorted in groups according to the back-calculated UTS of the fibers $(200,300,400,500,600,700$, and $800 \mathrm{MPa}$ ), and model lines are made using the variable $\sigma_{f 1}$ values, and a constant $\sigma_{m}$ of $50 \mathrm{MPa}$. It can be observed that the flax fibers in the study by Oksman ${ }^{29}$ and the flax fibers in the present study show $\sigma_{f 1}$ values of about $700 \mathrm{MPa}$ and $800 \mathrm{MPa}$, respectively. The remaining major part of studies shows $\sigma_{f 1}$ values in 


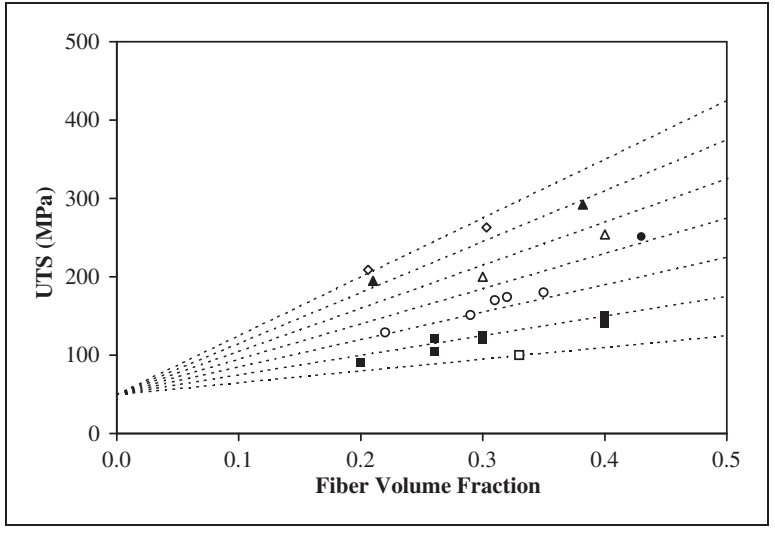

Figure II. Literature data on the axial ultimate tensile stress (UTS) of unidirectional natural fiber composites as a function of the fiber volume fraction. The data are grouped according to the back-calculated effective UTS of the fibers $\left(\sigma_{f 1}, \mathrm{MPa}\right): 200(\square)$, $300(\square), 400(\bigcirc), 500(\bigcirc), 600(\triangle), 700(\Delta)$ and $800(\diamond)$, and rule of mixtures model lines are made using the indicated $\sigma_{f 1}$ values, and a constant $\sigma_{m}$ of $50 \mathrm{MPa}$.

the range 200-500 $\mathrm{MPa}$. This demonstrates well the general finding that the strength of natural fibers in many cases is rather low. However, it also demonstrates that good-performance natural fibers can be produced with acceptable high effective strength values up to $800 \mathrm{MPa}$.

\section{Conclusions}

The presented detailed characterization and analyses of the properties and performance of unidirectional flax yarn/thermoplastic polyester composites show a number of findings:

- The good agreement between nominal and measured values of fiber volume fractions shows that the composite-manufacturing process is well controlled, which also is shown by the ability to manufacture composites with identical mechanical properties.

- The microstructure of the composites shows that the flax fiber yarns are well dispersed within the polyester matrix. The flax fibers are well impregnated with the polyester matrix, which is supported by the measured low porosity content in the composites. These findings are expected from the measured low degree of yarn compaction.

- In the axial direction of the composites, the tensile modulus and the UTS is increased linearly with the fiber volume fraction, as simulated by the rule of mixtures model. At a fiber volume fraction of 0.50 , tensile modulus and UTS are $32 \mathrm{GPa}$ and $350 \mathrm{MPa}$, respectively. Model calculations for glass/polyester composites show a slightly larger tensile modulus of $38 \mathrm{GPa}$, but a much larger UTS of $1800 \mathrm{MPa}$.
- As expected, due to the anisotropic nature of unidirectional composites, the tensile properties in the transverse direction are much lower than in the axial direction. By a rule of mixtures modeling of the tensile modulus of the composites in the two directions, the ratio of anisotropy of the flax fibers is estimated to be 13 .

- In the analysis of the weight-based performance of the composites, the specific tensile modulus of the flax/polyester composites is found to be larger than for glass/ polyester composites. For composites with a fiber volume fraction of 0.50 , the specific tensile modulus is 23 and $20 \mathrm{GPa} / \mathrm{g} / \mathrm{cm}^{3}$ for the two types of composites, respectively. Thus, for a given required stiffness, the flax fiber composites need a larger volume but will have a lower weight than the glass fiber composites.

- The analysis of results from previous studies of unidirectional natural fiber composites shows the typical span of reinforcement efficiencies for natural fibers ranging from 20 to $90 \mathrm{GPa}$ and from 200 to $800 \mathrm{MPa}$ for the tensile modulus and the UTS of the fibers, respectively. In this respect, the flax yarn fibers in the present study show very good reinforcement efficiency with a tensile modulus and an UTS of about $70 \mathrm{GPa}$ and $800 \mathrm{MPa}$, respectively.

Altogether, the obtained findings demonstrate that unidirectional composites with high-quality textile flax yarn in a thermoplastic polyester matrix has a good potential in structural applications when stiffness and weight-saving are the central selection criteria.

\section{Funding}

This work was partly funded by the EU seventh framework programme project: WOODY ('Innovative advanced woodbased composite materials and components').

\section{Acknowledgments}

The authors are grateful for the support given by Hans Lilholt, Tom L Andersen, Mustafa Aslan, Stergios Goutianos, Erik Vogeley, and Jacob Christensen at the Risoe National Laboratory for Sustainable Energy.

\section{References}

1. Bos HL, Oever MJA and Peters OCJJ. Tensile and compressive properties of flax fibers for natural fiber reinforced composites. J Mater Sci 2002; 37: 1683-1692.

2. Pratten NA. The precise measurement of the density of small samples. J Mater Sci 1981; 16: 1737-1747.

3. Andersen TL. Development of a rapid press consolidation technique for continuous fiber reinforced thermoplastic composites. In: Proceedings of the 18th Risoe international symposium on materials science, Risoe National Laboratory, Roskilde, Denmark, 1-5 September 1997, pp.237-244. 
4. American society of testing and materials. Annual book of ASTM standards. Part 35. D792. Specific gravity and density of plastics by displacement, 1980.

5. Madsen B. Properties of plant fiber yarn polymer composites. PhD Thesis, Technical University of Denmark, 2004.

6. Madsen B, Hoffmeyer P, Thomsen AB, et al. Hemp yarn reinforced composites-I. Yarn characteristics. Compos Part A: Appl Sci Manufac 2007; 38(10): 2194-2203.

7. Thygesen LG and Hoffmeyer P. Image analysis for the quantification of dislocations in hemp fibers. Ind Crop Prod 2005; 21: 173-184.

8. Hänninen T, Thygesen A, Mehmood S, et al. Mechanical processing of bast fibres: the occurrence of damage and its effect on fibre structure. Ind Crop Prod 2012; 39: 7-11.

9. Thygesen A, Madsen B, Bjerre AB, et al. Cellulosic fibers: effect of processing on fiber bundle strength. J Nat Fibres 2011; 8: 161-175.

10. Hughes M. Defects in natural fibres: their origin, characteristics and implications for natural fibrereinforced composites. J Mater Sci 2012; 47: 599-609.

11. Mustafa A, Carrasco GC, Soerensen BF, et al. Strength variability of single flax fibers. J Mater Sci 2011; 46: 6344-6354.

12. Madsen B, Thygesen A and Lilholt H. Plant fiber composites - porosity and stiffness. Compos Sci Technol 2009; 69: 1057-1069.

13. Madsen B, Lilholt $\mathrm{H}$ and Hoffmeyer P. Hemp yarn reinforced composites-II: tensile properties. Compos: Part A 2007; 38: 2204-2215.

14. Cichocki FR and Thomason JL. Thermoelastic anisotropy of a natural fiber. Compos Sci Technol 2002; 62: 669-678.

15. Page DH, El-Hosseiny F, Winkler K, et al. Elastic modulus of single wood pulp fibers. Tappi 1977; 60: 114-117.

16. Hepworth DG, Bruce DM, Vincent JFV, et al. The manufacture and mechanical testing of thermosetting natural fiber composites. J Mater Sci 2000; 35: 293-298.

17. Rong MZ, Zhang MQ, Liu Y, et al. The effect of fiber treatment on the mechanical properties of unidirectional sisal-reinforced epoxy composites. Compos Sci Technol 2001; 61: 1437-1447.

18. Sridhar MK, Basavarappa G, Kasturi SG, et al. Mechanical properties of jutepolyester composites. Indian J Technol 1984; 22: 213-215.

19. Hepworth DG, Hobson RN, Bruce DM, et al. The use of unretted hemp fiber in composite manufacture. Compos: Part A 2000; 31: 1279-1283.

20. Sanadi AR, Prasad SV and Rohatgi PK. Sunhemp fiberreinforced polyester. J Mater Sci 1986; 21: 4299-4304.

21. Shah AN and Lakkad SC. Mechanical properties of jutereinforced plastics. Fiber Sci Technol 1981; 15: 41-46.

22. Oksman K, Wallström L, Berglund LA, et al. Morphology and mechanical properties of unidirectional sisal-epoxy composites. J Appl Polym Sci 2002; 84: 2358-2365.

23. Madsen B, Lilholt H, Thygesen A, et al. Aligned flax fiber/polylactate composites-A materials model system to show the potential of biocomposites in engineering applications. J Nanostruct Polym Nanocompos 2009; 4: 139-145.

24. Kumar P. Mechanical properties of jute fibers and their composites. Indian J Technol 1986; 24: 29-32.

25. Roe PJ and Ansell MP. Jute-reinforced polyester composites. J Mater Sci 1985; 20: 4015-4020.

26. Van de Weyenberg I, Ivens J, De Coster A, et al. Influence of processing and chemical treatment of flax fibers on their composites. Compos Sci Technol 2003; 63: 1241-1246.

27. Madsen B and Lilholt H. Physical and mechanical properties of unidirectional plant fiber composites - an evaluation of the influence of porosity. Compos Sci Technol 2003; 63: 1265-1272.

28. Thygesen A, Thomsen AB, Daniel G, et al. Comparison of composites made from fungal defibrated hemp with composites of traditional hemp yarn. Ind Crop Prod 2007; 25: 147-159.

29. Oksman K. High quality flax fibre composites manufactured by the resin transfer moulding process. $J$ Reinforc Plast Compos 2001; 20: 621-627. 